\title{
FOCUS on technology-supported learning in further education
}

\author{
Janice Smith \\ Learning Technology Research Institute, University of North London \\ email:janice.smith@unl.ac.uk
}

This paper introduces FOCUS, a 'one-stop shop' for technology-supported learning resources designed and developed by a consortium of higher and further education partners. It reports on an investigation of the issues surrounding the adaptation of this $H E$-orientated resource to an FE context. This involved piloting FOCUS with FE staff to assess its suitability. The issues raised by this process are discussed and general implications for the adaptation of generic $H E$ resources to the $F E$ sector are identified.

\section{Introduction}

The Dearing Report of 1997 has raised the profile of the use of information and communications technology (ICT) in learning and teaching. This in turn has led to a demand for staff development on the successful incorporation of ICT in education (Smith and Oliver, 2000). In HE, there have been a number of targeted funding initiatives such as the Computers in Teaching Initiative (CTI) and the current third phase of the Teaching and Learning Technology Programme. This latter programme focuses on embedding learning technologies rather than developing software products, leading to generic projects on the implementation of ICT in education. As these projects aim for cross-institutional transferability, there seems no reason why - although carried out in the context of HE they should not be widened to address the needs of the FE sector.

This article will look at the expected expansion in FE (Blunkett, 2000) and aims to show how ICT (often referred to as Information and Learning Technology (ILT) in further education), allied to strategic goals, represents one potential solution to the challenges FE faces. It will then describe the TLTP3 FOCUS project and the efforts being made to broaden its appeal to the FE community. Feedback from a focus group is included to illustrate users' needs, and general issues in resource adaptation are identified. 


\section{FE and lifelong learning}

Further education in the UK has historically been underfunded (FEDA, 2000; Select Committee on Education, 1998) in comparison with other spheres of tertiary education, in spite of addressing a far broader curriculum offer (Kennedy, 1997). In addition, FE is now at the centre of government initiatives in lifelong learning and needs to find new ways of delivering an ever-broadening range of qualifications (HEFCE, 2000a) to students with an ever-widening range of abilities (Kennedy, 1997). Substantial funds are now available to the FE community to improve ICT infrastructure and invest in new technology, which is viewed as one important way of supporting learning. All colleges are required to produce an Information and Learning Technology (ILT) strategy document under the National Learning Network (NLN) initiative, and appoint staff as 'ILT Learning Champions'. A national training programme is under way to enable the new ILT Learning Champions to lead the way within their own college in promoting ILT for curriculum delivery. See the FE Resources for Learning Website http:/lferl.becta.org.uk for more information including the FEFC report Networking Lifelong Learning and FEFC Circulars 99/45 and 99/53. This suggests that wider use of ICT will become increasingly important with the closer collaboration of further and higher education institutions (HEFCE, 2000a) and that a greater proportion of higher education is likely to be delivered in FE colleges (Boreham and Morgan, 1999) with the introduction of two-year foundation degrees (HEFCE, 2000b).

We expect foundation degrees to appeal to a wide range of students. Given the vocational focus of these degrees, we anticipate that a high proportion of applicants will be employees seeking to open up new career horizons by enhancing their education and skills. These individuals are likely to want flexible modes of delivery such as part-time or distance learning provision that enables them to both 'earn and learn'. (HEFCE, 2000b)

Not only will the likely participants in foundation degrees be non-traditional, that is, parttime and distance learners, but delivery is increasingly likely to be undertaken by non-traditional teaching staff, accentuating an existing trend: by 1999, 63 per cent of FE lecturers were employed on a part-time basis (Tester, 2000), with a sector high of 92 per cent part-time lecturers in one FE college (Betts, 2000). If suitable levels of tutorial and personal support are going to be available to these new learners, many of whom will have been out of the education system for some time, the supportive features of ICT need to be better understood and well-deployed to ensure retention and achievement.

The proportion of part-time teachers in FE poses a challenge: how does the college schedule training programmes, either for the suggested mandatory teaching qualification or for improving ICT skills to the point where these lecturers can make use of the new technologies to support their new learners?

\section{ICT and learning}

For a long time, the use of ICT in FE has been measured by the ratio of computers to students, or investment in open access study areas that feature prominently in college marketing materials and prospectuses. However, 'mere provision of information technology does not in itself guarantee change; integration and management are necessary if particular education or organization outcomes are desired' (Tearle, Dillon and Davis, 1999). 
This point is important: simply introducing computers and expecting students to use them for coursework fails to take advantage of the benefits of the technology. It is widely acknowledged that well-planned integration of ICT (Draper, 1997; Laurillard, 1997) can provide flexible, supportive environments (Rowntree, 1992; Ehrmann, 1996; Race, 1994) to motivate students to extend their skills and knowledge. In addition, the potential of ICT use has been recognized to be of particular use to assist 'non-traditional' learners such as part-timers and distance learners through the use of synchronous and asynchronous tools to create support networks amongst such learners (Conole and Oliver, 1998; Mayadas, 1997).

Continued expansion and attraction of lifelong learners means these tools must now be better deployed within the curriculum: a recent survey sponsored by FEDA (http://www.citadel.ac.uk/) has demonstrated an investment in self-study materials within FE, but little incidence of virtual learning environments (VLEs). These tools can offer many kinds of support to the learner that will be important to cope with the expansion in FE provision noted above, including:

- asynchronous communication, where learners can $\log$ on and follow a 'threaded' debate at a time convenient to themselves;

- learner tracking systems, where lecturers can analyse their students' access to and progress through provided materials;

- secure content, available in a structured way to support the learner;

- Web links to quality-assured, freely available material;

- file-sharing to encourage collaborative work;

- online assessment, to reduce the marking burden on lecturers and provide instant feedback to learners.

To make best use of such facilities, however, strategic endorsement must support implementation and sufficient resources be provided for staff development. The development of ILT strategies in further education and learning and teaching strategies in higher education focus the need for appropriate, high-quality resources to prepare and support lecturing staff in implementing technology-supported learning. As Bailey (1996) identified, 'difficulty in identifying relevant materials' was a concern for those in $\mathrm{HE}$, which led him to identify four training needs:

- Awareness of how learning technologies could be used in teaching, learning and assessment.

- Knowledge and skills in the use of learning technologies in teaching, learning and assessment.

- Locating existing materials and assessing whether they would fit within your teaching.

- Developing skills in designing and producing computer-based learning materials.

His findings were confirmed by the TALiSMAN project, in that 'three-quarters of all staff, particularly in smaller institutions, do not feel that they know how to locate relevant network-based learning technology' (Tomes and Higgison, 1998). 
These concerns can apply equally to FE teaching staff (Carvalho, 1999; Smith, 1999). As much energy can be expended on similar initiatives in different institutions, it would make sense to customize generic resources produced by the HE community in response to the educational development needs identified above, in order to make them accessible and appropriate to FE. This is especially true now, with colleges developing their ILT strategies and the increasing number of VLEs available. The process of extending the potential audience is a stated aim of the FOCUS project, to assist the FE community in their implementation decisions.

\section{What is Focus?}

FOCUS is a TLTP3-funded project comprising the Universities of Portsmouth, Glasgow, Loughborough, North London and Southampton and Sheffield College. It has three main aims:

- to develop a Web-based database of learning and teaching techniques, tool reviews and case studies of interest to those wishing to use ICT in their teaching;

- to develop a set of staff development materials for those such as staff developers who support lecturers wishing to make use of ICT in their teaching;

- to disseminate these products to the widest possible HE and FE audience.

The FOCUS Web-based database is envisaged as a 'one-stop shop' for academics and educational technologists in further and higher education covering pedagogy, virtual learning environments and case studies of embedding C\&IT into learning and teaching. Its underlying framework is to provide differing levels of support dependent on the user's background and existing expertise (Oliver, Phelps and Conole, 1999). FOCUS aims to help users explore available resources, discover good practice and choose suitable technologies (Warren, 2000).

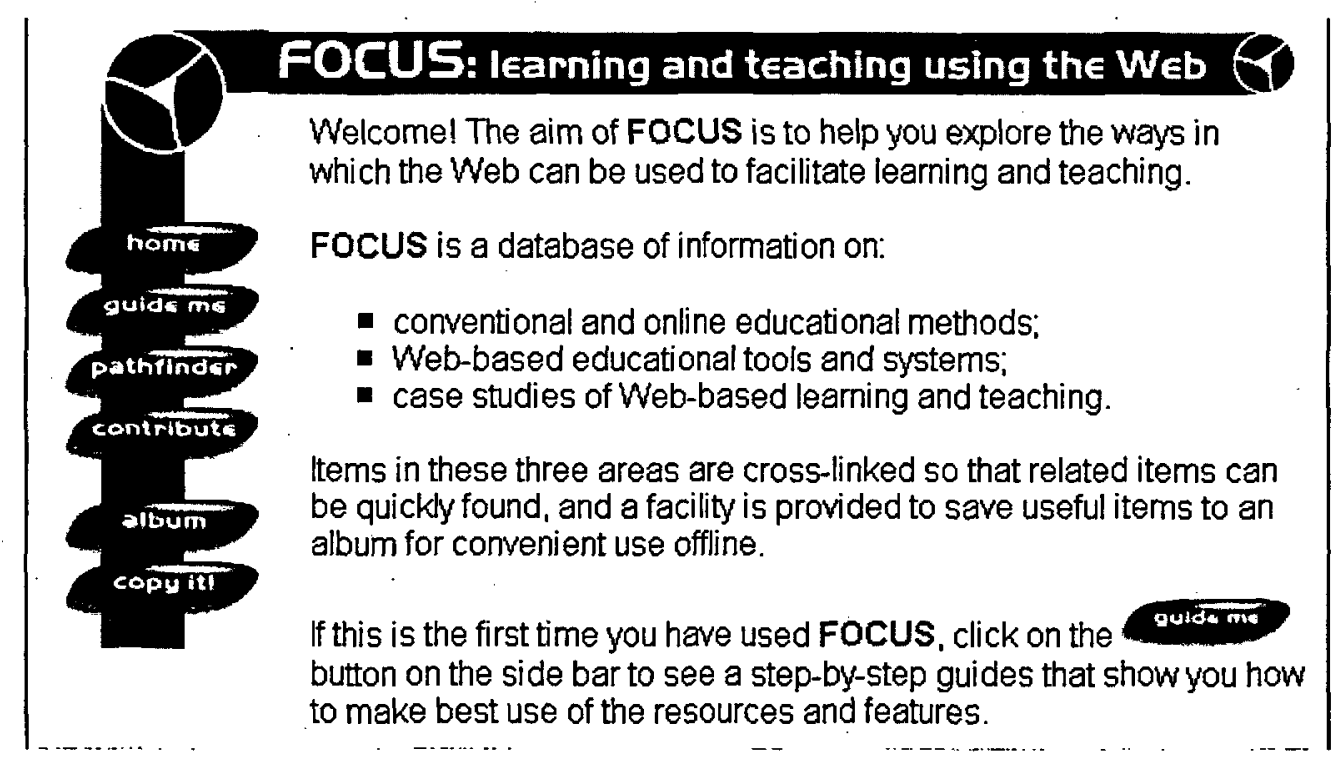

Figure 1: The FOCUS homepage. 
With increasing pressure on resources, the FOCUS database is intended as a useful vehicle to achieve learning and teaching innovation, to lessen the time it would take for practising academics to redevelop their courses using the new technologies. A set of staff development materials, downloadable from the project's Website, is also available in order that academics, staff developers and educational technologists can access and use the database independently.

\section{FOCUS features}

To ensure that the complexity of a Web-based database is invisible to novice users, the FOCUS database functionality is presented as a set of easy-to-use features, accessed via clickable buttons, described below.

\section{Locking}

This feature enables users to locate information of interest by using a limited search facility. Through the use of keywords, each category (learning, tools and examples) can be 'locked' to facilitate searching so that, for instance, only tools that support intended teaching activities are displayed.

\section{Copy-lt!}

Integrating ICT into learning and teaching activities is a complex activity. The information contained within FOCUS reflects this and can often be lengthy. To avoid users having to scroll through reams of text the Copy-It! function was included. When a user finds an article of interest, a simple click copies it to a personalized album.

\section{Album}

An album is a collection of articles of interest that is emailed to the user, to avoid the need to absorb too much information in one visit. The album can be viewed and the contents printed or deleted before being emailed to keep for future reference.

\section{Contribute}

FOCUS relies on participation. There are examples of good practice in a variety of subjects and contexts that are valuable to others investigating ICT, and new tools appear regularly. Interested parties can provide information via the Contribute button to share what has been learned - what has worked well and maybe even what has not - with the wider community. Contributions to content are actively encouraged and acknowledged, as the database will only remain relevant if new material is contributed by developers and practitioners on an ongoing basis. Copyright remains with the author. All content supplied to FOCUS is moderated by project team members.

\section{Discussion forum}

Those with an interest in online teaching and learning can join the FOCUS mailbase list at tltp-focus@mailbase.ac.uk or the WebBoard forum that can be accessed from the FOCUS Website.

\section{Using FOCUS}

FOCUS is freely available via the Web (htttp://www.focus.ac.ukl) for interested staff developers and academics. Staff development materials and an evaluation questionnaire are available from the project's Website (follow the link from the database homepage); 
feedback and comments are welcome, especially from the FE sector. Evaluation of the database will continue until December 2000, after which, if sufficient demand can be demonstrated, FOCUS may be adopted as part of a core of generic resources to inform technology-supported learning developments within the tertiary sector.

\section{Using FOCUS for staff development}

'Graduateness', 'employability' and participation in the 'information society' are important issues for the UK education system, and a central theme to each of these concepts is 'ICT capability' (Boreham and Morgan, 1999). There is no single definition of ICT capability, but if it is to go beyond mere word-processing skills, teaching staff in FE and $\mathrm{HE}$ will need a sound understanding of the pedagogic issues involved and how technology-supported learning will change their roles. FOCUS aims to do this by providing a staff development resource that introduces teaching staff to the navigation and use of the database. It is expected that individuals will follow up this introduction by further interrogation of the database content with regard to their particular interest.

Following initial development, FOCUS was piloted within the HE community, and Table 1 (below) shows responses from thirty-seven workshop participants. The evaluation of FOCUS's development found that for teaching staff, use of FOCUS is likely to mean investigating teaching techniques and case studies of innovations in practice. For technical and support staff, the features and capabilities of particular VLEs are more likely to be of interest.

\begin{tabular}{lcc}
\hline & \multicolumn{2}{c}{ \% agreeing } \\
Option & Teaching & Non-teaching \\
\hline Information required by the examples in the staff development materials & 39 & 38 \\
Information about teaching techniques of interest & 78 & 46 \\
Information about case studies of relevance & 61 & 31 \\
Information about software tools you might use & 39 & 69 \\
\hline
\end{tabular}

Table 1: How FOCUS was used.

Feedback was positive from these sessions, with participants making constructive suggestions for amendment and inclusion, including a need to tailor activities to specific audiences. The navigational structure was found to be mostly helpful, and a majority of participants liked the breadth of content. When asked 'what was the most useful part of the session for you?', over half said 'the URL'. Lecturing staff are increasingly being expected to make use of technology-supported learning and, therefore, need to investigate resources such as FOCUS to become aware of the many possible tools to support their specific circumstances. The most useful addition suggested by the HE audience was the inclusion of locally available resources and support. In response to this, the development team is adding profiles of their expertise, but FOCUS must be seen as a generic resource, allowing individual institutions to make available information on supported tools and expertise to allow technology-supported learning closely to match local needs. 


\section{Adapting FOCUS for an FE audience}

As noted earlier, FOCUS was committed from the outset to involve FE as part of its intended user base. Therefore, in the latter stages of the project, dissemination was undertaken in the FE community to raise awareness and encourage FE contribution to the established HE content. Two pilot sessions were conducted, one for content comment and one for staff development material design, in order to assess how well the database met the needs of their group. Valuable feedback was gained regarding these issues, to improve the usefulness of the resource for an FE audience.

At the outset of the FE pilot sessions, FOCUS's HE origins were declared, along with the intention that the database aimed to reflect $\mathrm{FE}$ needs and incorporate relevant content. The FE audience was invited to be a 'critical friend' to the project to suggest refinements and additions in order that FOCUS better reflected their needs and concerns. Each of the topics identified during these sessions is discussed further below.

\section{Design}

Overall, the interface was considered intuitive, if a little rigid. Anomalies in, for instance, the interchangeable use of the terms 'teaching' and 'learning' were found to be irritating. The integral Guide Me feature, where many FE participants started their investigation, was declared 'confusing' in terms of its inconsistent formatting. In terms of supported use, the Guide $M e$ is a useful introduction. However, its visual similarity to the real database meant users could not easily locate their position within the FOCUS framework. It was also felt that the Guide $\mathrm{Me}$ feature did not fully explain the functionality of the database, such as its locking mechanism, or the Copy-it! and Album features. Further discussion of this last point revealed that people often saved useful Web pages, but found themselves, for whatever reason, unable to open them in the future. An explicit explanation, that a collection of articles can be emailed to a user for future reference, would enhance the Copyit! and Album features, as would feedback that articles had been copied successfully.

\section{Content}

The length of some of the articles was also found to be a barrier to greater FE take-up: 'it's very accessible to $\mathrm{HE}$ people who are used to this kind of academic presentation. It needs to be more "tabloidy" for FE.' Interestingly, this led to a suggestion that an additional button could be included for FE users to click to access shorter, snappier articles, including 'a jazzy box, sort of "did you know" reflecting conclusions from case studies, important points'. This remark supports a project team suggestion to include a 'tried that, didn't work' section.

The extremely limited time or support in FE for research means that lecturers need easily accessible information and support to address a 'problem', usually via subject-specific channels. Many FE concerns are addressed within the text of the HE content, but these are felt to be too lengthy. To increase accessibility for FE staff it may be useful to encourage FE content that conforms to something like the LTDI Evaluation Cookbook (http://www.icbl.hw.ac.uk/ltdi) - recipes that address the parameters of what a particular technology can achieve in terms of time, resources and scalability.

\section{Relevance}

Alongside the previously noted point about the length of some articles and their academic presentation, there was a concern to know that content was up to date: 'We need to know 
that it's frequently updated and can offer us something new.' This was followed by a suggestion for a 'News' button that 'could highlight what's new in the last six months'. It is worth noting that a concern of the project team is that content is accepted as current best practice, and an automated system of email alerts to authors has been instigated to ensure regular updates.

FE participants also said they would appreciate brief introductions to the range of software available. It was felt that the full reviews would certainly be useful to technical and support staff but that these are less of a concern to lecturing staff. This reinforces the point that locally available information about supported tools is an important concern. The database does offer a software 'feature checklist' but this is felt to be deeply embedded within a technical evaluation that does not appeal to teaching staff.

The most positive feedback from FE was reserved for the links from the database to other projects and/or Websites such as the Clyde Virtual University (http://www.cvu.ac.uk) and the CAA Centre (http://www. caacentre.ac.uk). These were declared to be 'great fun - but we need more of them'.

In the 'free' part of the staff development session, FE staff followed a similar pattern to that noted amongst $\mathrm{HE}$ users - teaching staff investigated the teaching techniques whilst support staff followed the 'Tools' link. Both categories of staff perused at least one case study, with the only FE-provided article (LeTTOL, from Sheffield College) proving most popular.

\section{Staff development materials}

The first of the two FE dissemination sessions was undertaken with a set of pilot materials in the form of a Powerpoint presentation. These materials were adapted from an initial pilot of WebCT sessions within the project team.

This original set of materials was felt, within the FE sector, to be serving two purposes: an introduction to the use of FOCUS and addressing strategic issues relating to the use of

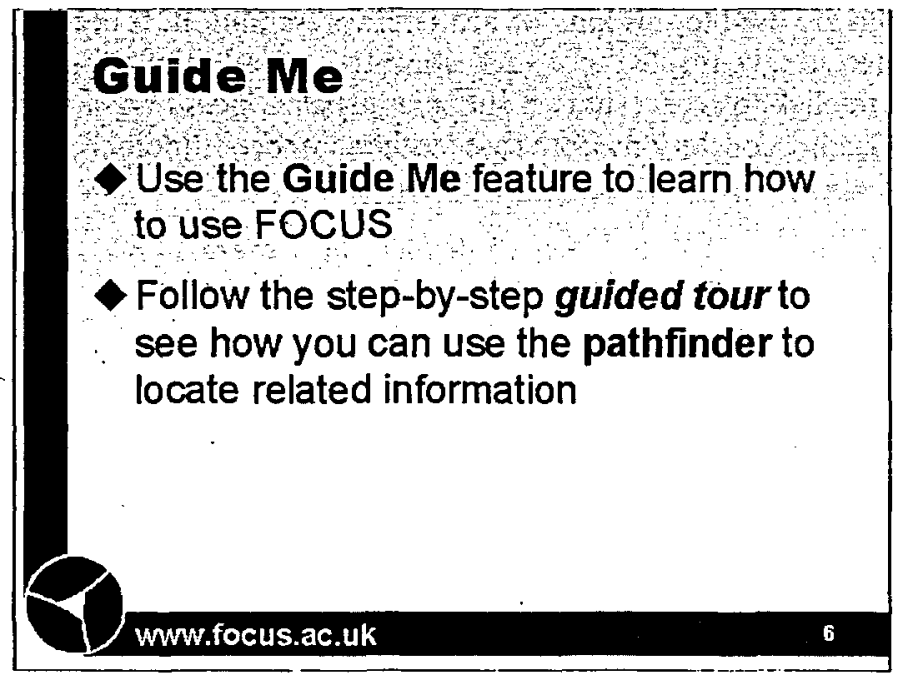

Figure 2: The Guide Me tool. 
Figure 3: The original learning objectives.

\section{Learning objectives}

After this session you should be able to:

- define the purpose of FOCUS;

state the main objectives of FOCUS,

- describe the features of FOCUS;

- demonstrate how FOCUS can be used;

- explain how FOCUS might be used to develop your teaching practice.

\section{Applicability}

Identify the most appropriate tool(s) to support a teaching activity

You may like to consider:

Organisational issues

- Technological issues

- Startup costs - hardware, sofware, training

- Staff and student training needs

- Pedagogy - learning and teaching online

Figure 4: The applicability exercise.

ICT in learning and teaching. The guide to using FOCUS was felt to be incomplete (see Figure 2) as the major functional features of the database were not sufficiently explained. Also, the learning outcomes were deemed inappropriate (Figure 3) as they appeared to enumerate project concerns over what the audience should consider when implementing technology-supported learning.

In addition, the 'Applicability' exercise (see Figure 4) was felt to be aimed at a different audience, specifically strategic management rather than teaching and support staff. Similar views were expressed during HE dissemination.

In response to this feedback, the Powerpoint presentation was refined. Amongst project team members, it was felt that a comprehensive introduction to FOCUS content and navigation would be useful, and the slides reflected this concern. Figure 5 shows the 


\section{Learning outcomes}

After this session you should be able to: describe the types of resources avallable in the Focus database

locate relevant resources using FOCUS find related resources within FOCUS copy resources for later reference

Figure 5: The redefined learning outcomes for the FE oudience.

\section{Finding related resources}

Suppose you re reading about $\mathrm{CAA}$

(Computer Assisted Assessment) and

want to look at relevant case studies:

- Click on the red spot on the learning button to lock CAA.

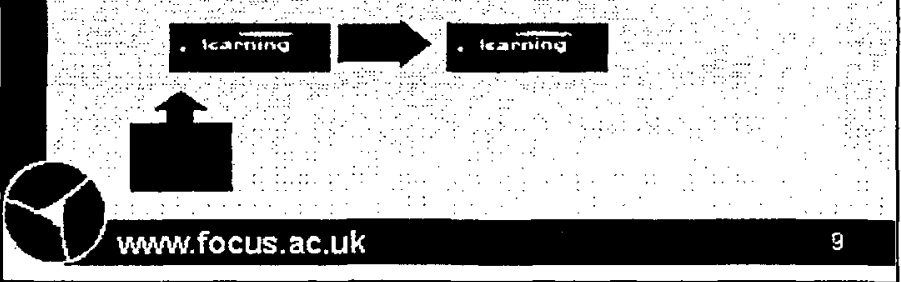

Figure 6: Explaining the features of FOCUS.

redefined learning outcomes, and additional slides were created to introduce users to specific database functions (Figures 6, 7,8 and 9).

The second FE session used the refined presentation, and this was felt to reflect more closely what lecturing and support staff would want to know about accessing and interrogating FOCUS, although the addition of a free search tool was considered 'essential'. However, the FE staff developer was in favour of creating a further session addressing the strategic issues that had now been abandoned, a position supported by a member of the project's steering group. Concerns in the FE sector mirror those found in HE: the lack of time and other resources - human and otherwise - to pursue technologysupported learning. This issue will be addressed in the final development and evaluation phase of the project, and aims to draw upon existing expertise in the FE sector. 
Figure 7: Using the lock feature.

\section{Finding related resources 2}

Once CAA has been locked

$\checkmark$ click on the tools button

$\checkmark$ click on the examples button to see a list of case studies that involve CAA

- click on an item to find out more about these tools or examples

click again on tools or examples to redisplay the list of relevant items

Figure 8: Relating tools and techniques.

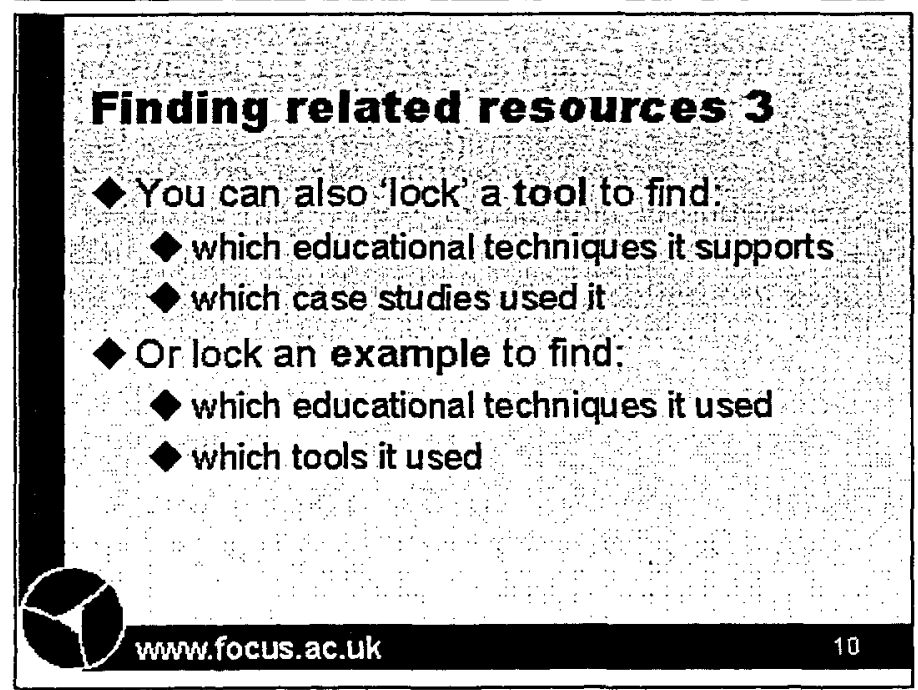

\section{Conclusions}

FOCUS has been greeted enthusiastically by an HE audience, with 94 per cent of survey respondents saying they would continue to use the database. As many as 94 per cent also said they would recommend it to a colleague. A total of 83 per cent of teaching and 50 per cent of non-teaching staff stated that they had learnt something new about using computers to support learning and teaching. FOCUS is clearly a useful and valuable resource in the HE community. With greater awareness and contribution from the FE sector, it is hoped to replicate this kind of acceptance. Importantly, many of these conclusions will be equally relevant for other projects seeking to extend their scope to cover an FE audience. To date, the lessons learned include:

- Be explicit about technical jargon/terminology such as 'Copy it', 'Album' and 'Locking': these are useful features that require full explanation if staff developers from outside 


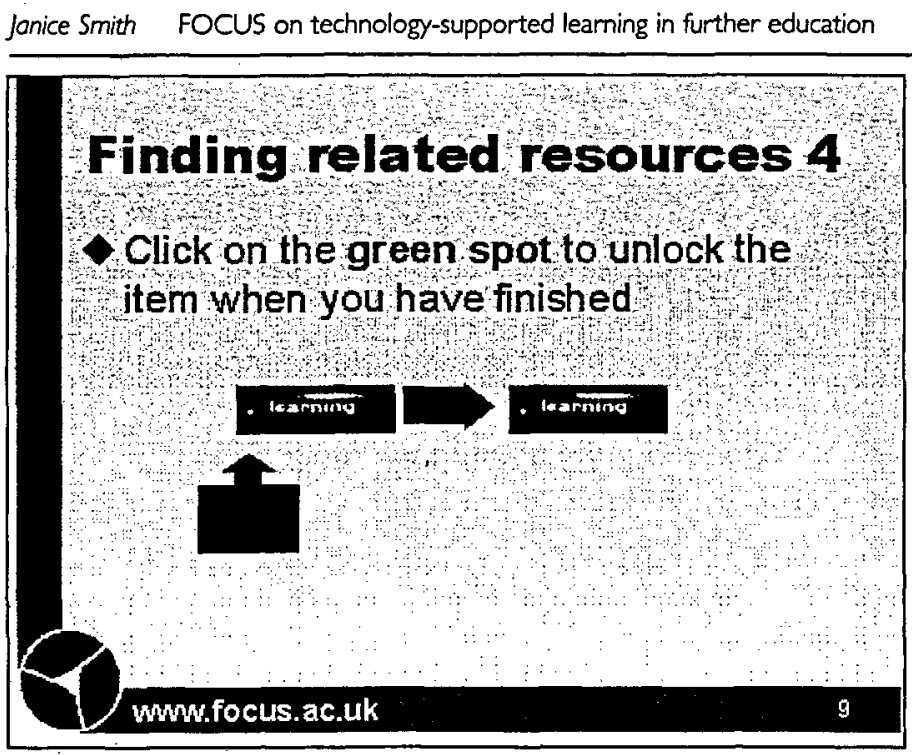

Figure 9: Unlocking to explore other areas.

the project consortium are to ensure participants understand the full functionality of the database.

- Provide summaries of content: whilst HE staff are familiar with the academic presentation of information, the FE staff consulted preferred summaries of content, such as the suggestion of a shorter 'hints and tips' section. Time pressures mean that in order to adopt technology-supported learning, FE staff need to know which tools and techniques will best support their particular needs.

- Highlight what's new: of importance to both FE and HE staff is knowing that this information is up-to-date and reflects current good practice.

- Distinctive audiences: it may be necessary to separate groups of users according to their interests and remit, such as strategic management and teaching/support staff. Costs and benefits need to be taken account of at senior management level, whilst complexity and 'fit' to purpose for lecturing staff and support requirements for learning support/technical staff are important issues. FOCUS as a one-stop shop offers invaluable information to each group, but targeted training is required for each distinct group, an issue common to both $\mathrm{FE}$ and $\mathrm{HE}$ audiences.

FE activities will continue in the final evaluation phase of the project in order to ensure its wide acceptance and appropriateness for this sector.

In summary, many of HE's concerns about incorporating technology-supported learning into the curriculum are reflected in the FE sector, and will assume greater importance as the proportion of $\mathrm{HE}$ delivered in the FE sector continues to grow. Greater specialization of roles and lowering units of resource have accentuated these issues still further. Investment in technology-supported learning in $\mathrm{HE}$ is now key to many institutional learning and teaching strategies. It is useful to explore how far knowledge about, and support for, such innovations can be extended to an expanding FE sector. 


\section{Acknowledgements}

My thanks to Dr Martin Oliver for his comments on a first draft of this paper, Lucy MoyThomas and colleagues at Barking College for their comments, and to the FOCUS project team for their design and development work.

\section{References}

Bailey, P. (1996), Attitudes to Technology in Teaching, Learning and Assessment, http://www.sh.plymouth.ac.ukleds/tsl/skiltext.htm.

Betts, D. (2000), Report on a Functional Analysis of the Part-time lecturers in Colleges of Further Education - their Roles and Characteristics, http://www.fento.org/roles-andcharacteristics.pdf.

Boreham, N. C. and Morgan, C. (1999), 'Curricula for information and communication technology in higher education', unpublished report to the ESRC, Project No. R000222675.

Blunkett, D. (2000), 'Modernising higher education - facing the global challenge', speech given at the University of Greenwich.

Carvalho, P. (1999), 'Creation of an extranet for health and social care', QUILT development project at the College of North West London. FEDA.

Conole, G. and Oliver, M. (1998), 'A pedagogical framework for embedding C\&IT into the curriculum', ALT-J, 6 (2), 4-16.

Draper, S. (1997), 'Prospects for summative evaluation of CAL in higher education', ALT-J, $5(1), 33-9$.

Ehrmann, S. C. (1996), Information Technology and the Future of Post-Secondary Education, Paris: OECD.

FEDA (2000), The Learning and Skills Councils: Funding Flows and Business Processes, http://www.feda.ac.uk.

HEFCE (2000a), HEFCE Invites Proposals for Development of Foundation Degrees, press release, http:/lwww.hefce.ac.uk/news/default.asp?Page=HEFCE/2000/fdinv, July 2000.

HEFCE (2000b), Foundation Degree Prospectus, http://www.niss.acukleducation/hefcel pub00100_27.html.

House of Commons Select Committee on Education and Employment (1998), Sixth Report, http:I/www.parliament.the-stationery-office.co.uk/palcm199798/cmselect/cmeduempl 264/26408.htm.

Kennedy, H. (1997), Learning Works - Widening Participation in Further Education, FEFC.

Laurillard, D. (1997), 'Technology for distance learning: organisational infrastructure', Paper presented to UCISA 1997 Management Conference, http://www2.open.ac.uk/LTTI ucisapre.htm.

Mayadas, F. (1997), ‘Asynchronous learning networks: a Sloan Foundation perspective, 
Journal of Asynchronous Learning Networks, 1 (1), http://www.aln.orglalnwebljournall issuellmayadas.htm.

National Committee of Inquiry into Higher Education (1997), Higher Education in the Learning Society, The Dearing Report, London: HMSO.

Oliver, M., Phelps, J. and Conole, G., (1999), An Evaluation Strategy for the FOCUS Project, FOCUS Report No. 1, University of North London.

Race, P. (1994), The Open Learning Handbook: Promoting Quality in Designing and Delivering Flexible Learning (2nd edn), London: Kogan Page.

Rowntree, D. (1992), Exploring Open and Distance Learning, London: Kogan Page.

Smith, J. (1999), 'The effective implementation and integration of resource-based learning in post-16 vocational education', unpublished internal report, Barking College.

Smith, J. and Oliver, M. (2000), 'Academic development: a framework for embedding learning technology', International Journal of Academic Development, 5 (2).

Tearle, P., Dillon, P. and Davis, N. (1999), 'Use of information technology by English university teachers: developments and trends at the time of the National Inquiry into Higher Education', Journal of Further and Higher Education, 23 (1).

Tester, N. (2000), 'Not up to scratch', Guardian Further Education, July 2000.

Tomes, N. and Higgison, C. A. (1998), 'Exploring the network for teaching and learning in Scottish higher education - TALiSMAN training needs analysis', unpublished report to SHEFC. http:I/www.talisman.hw.ac.uk/tnal.

Warren, A. J. (2000), FOCUS staff development materials, http://www.focus.ac.uk/cfdocs/ focus/project/sedintro.htm. 